\title{
The Tension between Stabilized Cooperation and Intensified Competition: Greening of Technological Frames in Practice
}

\author{
Fatemeh Saadatmand \\ University of Borås \\ fatemeh.saadatmand@hb.se
}

\author{
Rikard Lindgren \\ Swedish Center for Digital Innovation \\ University of Gothenburg \\ University of Borås \\ rikard.lindgren@ait.gu.se
}

\begin{abstract}
Cooperation and competition have traditionally been considered separate modes of interaction between firms. Recent research, however, observes that firms simultaneously engage in cooperation and competition with each other. Still the interplay of these modes is under-researched and surprisingly little is known about the nature of 'coopetition'. Our objective with this paper is to build new revelatory theory on the various facets of coopetition in vertical IT standardization and discuss their respective implications for environmental sustainability. We rely on an eleven-year study of a standard development effort aimed at greening the Swedish road haulage industry. Framing analysis is applied to scrutinize relations between cooperative modes and competitive behaviors of participating firms. The findings help explicate how and why stabilized cooperation may render intensified competition that undermines IT standardization efforts to green an industry. Our theorizing about this paradoxical tension paves the way for future network studies of coopetition dynamics in converging industries.
\end{abstract}

\section{Introduction}

Cooperative interorganizational settings such as strategic alliances, joint ventures, and value networks represent viable forms of communication between heterogeneous industry partners $[8,15,16]$. Because the partners often are competitors these forms have their own particular complexities. To illuminate and theorize such complexities as well as attempts to overcome them, previous research has studied the simultaneous emergence of cooperation and competition $[8,9,11,27,32,45,46]$.

Despite that coopetition received increasing attention recently, these two organizational modes have largely been studied separately. This means that the literature on cooperation has evolved almost independently of the literature on competition. It is therefore a need for studies that carefully explore the intricate interplay between these two modes and theorize the different patterns of their coevolution. Of particular interest is to identify what antecedents, mechanisms, and consequences that drive their interplay [23]. Prior work suggests environmental sustainability to be a useful setting for studying how intertwined mechanisms of cooperation and competition unfold [39]. A prerequisite for promoting environmentally conscious behavior in large-scale greening efforts is the development of models, processes, routines, and IT systems that allow competing supply chain actors to share information and coordinate actions $[17,31,35,38,48]$.

So far research contributions have been primarily conceptual in nature; they have developed propositions rather than empirical insights into what it actually takes for competitors to collectively green an industry. In contrast, Delmas et al. [14] report an empirical study that zooms in on voluntary agreements as means to spur positive environmental sustainability performance. They recognize cooperative modes in greening projects, but undertheorize competition dynamics in collective action. Despite these shortcomings, however, received theory on the coexistence of cooperation and competition in environmental sustainability still offers a useful conceptual backdrop for generating new theoretical insights about coopetition.

In this paper, we identify and conceptualize the paradoxical tension [28] between stabilized cooperation and intensified competition in IT standardization efforts to green an industry. In particular, we seek to theorize not only the ways in which coopetitive action unfolds in such settings, but also how efforts to reduce resource heterogeneity may culminate in intensified competition between technological clones, especially after a standard has emerged and cooperation within the industry has been stabilized [cf. 37]. Indeed, academics and practitioners alike benefit from a better understanding of this tension and its potential consequences.

To leverage building of new revelatory theory, we rely specifically on Delmas et al's [14] framework of 
cooperation and literature on competition repositioning [e.g., 47]. This provides us with an initial understanding of coopetition in greening efforts, which frames our overarching research question: What are the facets of coopetition in vertical IT standardization and their respective implications for environmental sustainability?

To answer our research question, we analyze an eleven-year (2002-2012) action research study of a standardization effort in the Swedish road haulage industry that led to a new anticipatory vertical IT standard. On a practical level, the project aimed to identify and resolve problems surrounding the adoption of embedded, mobile, and stationary technologies. The main problem identified was the existence of proprietary and incompatible IT systems that hampered attempts to connect mobile field operations and stationary headquarters operations within and across road haulage firms $[2,30]$.

Given the lack of standardized ways to integrate the involved heterogeneous technologies into shared digital infrastructures, the Mobile-Stationary Interface (MSI) Group (IT vendors, road haulage firms, third-party developers, and truck manufacturers), industry representatives, and action researchers jointly developed a new vertical IT standard [3]. By aligning the array of embedded, mobile, and stationary IT systems that proliferated the industry, the MSI standard was expected to enable environmentally sustainable transport practices such as load sharing across firms, route optimization, and the monitoring of driver behavior.

\section{Literature Review}

\subsection{Environmental Sus tainability}

Apart from the aforementioned work by Delmas et al's [14], there is surprisingly little theorizing on environmental sustainability in the technology management and organization science discourses. In contrast, however, we have recently seen a growing interest among IS researchers to study pertinent questions evolving around technology-enabled greening efforts.

Building on the Belief-Action-Outcome framework, Melville [35] offers a research agenda on IT innovation for environmental sustainability. It focuses on informing beliefs, enabling actions, and transforming outcomes, and calls for IS research on incentive structures, systems modeling, and integrated assessment. Elliot [17] proposes an impact-oriented, transdisciplinary, and multifaceted conceptual model for business transformation. It categorizes the environment and five types of stakeholders as separate yet interactive systems within a single ecosystem. In the same vein, Watson et al. [48] develop a new IS perspective, energy informatics, that concerns the analysis, design, and implementation of IT to increase the efficiency of energy demand and supply systems. The underlying idea is that energy plus information equals less energy, which requires a common information system that spans supply and demand. This invites to a single system approach to environmental sustainability. Further, Watson et al. [48] suggest that three types of technology components should be present in an intelligent energy system: flow networks, sensor networks, and sensitized objects. An information system ties together the various components to provide an integrated IT solution supportive of environmental sustainability. Such a system can be deployed to achieve three broad sustainability goals: eco-efficiency, eco-equity, and eco-effectiveness.

While these contributions largely deal with the role of IT in attempts to reduce energy consumption $\left(\mathrm{CO}_{2}\right)$, they suggest successful development of models, processes, routines, and technologies that enable competing supply chain actors to share information and coordinate actions is at the heart of environmentally sustainable business processes [17, $31,35,38,48]$.

\subsection{Interfirm Coope tition}

Cooperation between stakeholders of different structural types, typically having diverging interests, is thus the key to leveraging green practices. In this context, however, one pressing issue concerns the establishment of coopetition among organizations, which renders concurrent cooperation and competition $[22,45]$. Coopetition is a reasonably new concept coined for framing situations where the organizational modes of cooperation and competition occur simultaneously [36]. Consequently, it breaks with the classical assumption that relationships between firms are either cooperative or competitive in nature [46].

To view cooperation and competition as a duality rather than a dualism has proven to be a powerful strategy for theorizing collective action in firm networks [45] as well as inter-firm networks [8]. However, the literature on cooperation has evolved almost independently from the literature on competition, which means that the interplay between cooperation and competition is largely underresearched [23]. 


\subsection{Vertical Standardization}

We surmise vertical IT standards initiatives to be excellent milieus for theory building that advances the current understanding of coopetition in largescale efforts for environmental sustainability. These IT standards prescribe data structures and definitions, document formats, and business processes for particular industries [33, 49]. Bala and Venkatesh [5] note that such standards "not only specify and define the structure and format of business messages through a common language but also orchestrate the message exchange choreography, i.e., sequence of steps required to execute an atomic business proces $s$ among trading partners". Embodying specific collaboration needs of a certain industry or groups of organizations, they thus serve to describe procedures and practices that should be followed to achieve a desired outcome.

The variety of the technologies and stakeholders involved constitutes a complex and rapidly changing environment. Such initiatives, however, need to encompass heterogeneous groups of IT vendors and user organizations without fragmenting [34]. Whereas vertical IT standardization usually requires concurrent cooperation and competition, the success of these standards is often a result of cooperation between different stakeholders that both compete and complement each other. That is, standardization efforts that evolve into rival, homogeneous groups are less likely to develop a standard that wins industry acceptance [34]. Industry consortia or fora are therefore established to coordinate the implementation of vertical IT standards in the marketplace by swiftly exploiting commercial possibilities. The anatomy of a consortium reflects the stakeholders of the standard being developed and it relates to the value networks embedded in the industry in question.

The history of standards development, however, suggests that many initiatives fail as a result of coopetitive relationships being competition-dominant [7]. Garud et al. [18] note that "cooperation among members of a standards collective is uneasy at best" and that "inducing and maintaining such a collective is a challenge even for a neutral body". This observation begs the question as to whether coopetition can be leveraged by vertical standard development so that environmental sustainability is promoted. To our knowledge there is no prior IS research that has addressed this question by exploring the various facets of coopetition and their respective implications.

\section{Research Setting}

The empirical setting of this research is the Swedish road haulage industry. Road haulage firms typically consist of mobile field operations and stationary headquarters. Digital infrastructures for such organizations therefore contain embedded, mobile as well as stationary computing resources [2]. The corresponding technological realms are commercial telematics, nomadic devices, and enterprise planning.

Embedded IT systems serve different purposes for various users. For example, digital services that utilize vehicle data to display feedback metrics on the performance of the vehicle for the driver may raise awareness of fuel consumption. Managers responsible for fleet performance can use the recorded digital traces of fieldwork to minimize the cost of a transport assignment in terms of time and fuel expenditure. Stationary IT systems help dispatchers remotely coordinate assignments by displaying the positions of individual trucks and by communicating associated information to drivers via integrated mobile IT systems. Embedded GPS-based positioning systems enable dispatching and in-vehicle navigation services. Table 1 presents a summary of classes of IT support in road haulage firms.

Historically, the lack of standardized interfaces for integration of embedded, mobile, and stationary IT systems has undermined Swedish road haulage firms' attempts to innovate digital infrastructures [3, 2]. While lock-in effects of proprietary interfaces created gaps between social and technical elements within firms, they also hindered interfirm partnership arrangements. It was therefore difficult to reduce $\mathrm{CO}_{2}$ emissions by improving fleet utilization and implementing flexible logistics operations.

To answer our research question, we rely on an eleven-year (2002-2012) industry effort that sought to develop and diffuse a vertical IT standard, referred to as MSI (Mobile-Stationary Interface), whose purpose was to seamlessly integrate the actors and technologies that constituted the Swedish road haulage industry. By aligning the array of proprietary and incompatible embedded, mobile, and stationary IT systems that proliferated the industry, the MSI standard was expected to enable environmentally sustainable transport practices such as load sharing across firms, route optimization, and the monitoring of driver behavior [3].

The standardization network consisted of the Viktoria Institute, road haulage firms, IT vendors, third-party developers as well as truck manufacturers. Powerful representatives of these stakeholders were all committed to the standard and its green objectives 
from the outset. Divergence in commercial interests, organizing visions, and design preferences, however, posed considerable challenges to the industry effort. Indeed, the fact that the participants perceived environmental sustainability differently added further complexity.

\section{Research Design}

Informed by our initial theorizing of coopetition we analyze this multi-year process through extensive field data such as repeated interviews with participants, documents, emails, and observational notes from design workshops and project meetings. Table 1 outlines a complete list of data sources.

\begin{tabular}{|c|c|}
\hline Data sources & Amount \\
\hline Interviews & $\begin{array}{c}133 \\
(80 \mathrm{~min})\end{array}$ \\
\hline Project meetings & $\begin{array}{c}30 \\
\text { (Average: } 240 \mathrm{~min} \text { ) }\end{array}$ \\
\hline Work meetings & $\begin{array}{c}75 \\
\text { (Average: } 120 \mathrm{~min} \text { ) }\end{array}$ \\
\hline Workshops & $\begin{array}{c}18 \\
\text { (Average: } 300 \mathrm{~min} \text { ) }\end{array}$ \\
\hline Board meetings & $\begin{array}{c}17 \\
\text { (Average: } 75 \mathrm{~min})\end{array}$ \\
\hline $\begin{array}{l}\text { Emails (dealt } \\
\text { exclusively with } \\
\text { substantive is sues) }\end{array}$ & 267 \\
\hline $\begin{array}{l}\text { Presentations (Word } \\
\text { documents, power } \\
\text { points) }\end{array}$ & 83 \\
\hline Project applications & 9 \\
\hline Decision letters & 5 \\
\hline $\begin{array}{l}\text { Strategy documents (IT } \\
\text { vendors, MSI group) }\end{array}$ & 32 \\
\hline $\begin{array}{l}\text { Technical documents } \\
\text { (IT vendors, MSI group) }\end{array}$ & 21 \\
\hline System demons trations & 18 \\
\hline Standard applications & 22 \\
\hline Environmental reports & 14 \\
\hline Module specifications & 12 \\
\hline Press releas es & 12 \\
\hline Popular press articles & 11 \\
\hline
\end{tabular}

\section{Table 1. MSI data sources}

We started the analys is by distinguishing between modes of cooperative behavior [14] that emerged throughout the IT standardization process. Delmas et al. [14] identify and conceptualize three such modes in greening efforts: noncooperation (firms that did not participate in the voluntary agreements), symbolic cooperation (firms that participated in the voluntary agreements, but did not improve their environmental performance significantly more than nonparticipants), and substantive cooperation (firms that participated in the voluntary agreements and improved their environmental performance). Having analyzed the data based on the different cooperative modes, we sought to scrutinize competition-driven repositioning $[10,19,20,40,47]$ in each of these modes by help of a contentious framing lens [4].

Framing analysis has previously been conducted to analyze effects of power imbalances in collective action $[4,13]$ and social behavior [6]. We have relied on a signature matrix to specify the frames that participants held at different points in time and undertook theme analysis in the selection process by using Leximancer (content analysis software). Our frame analysis can therefore be understood in terms of frame dynamics (evolution) where the interaction between 'opportunity-based frames' and 'threatbased frames' shaped the emergence of coopetitive relations between cooperative modes and competitive behaviors. This evolution both enabled and constrained the greening process of frames necessary for the MSI standard to enable environmentally sustainable transports. Here we were particularly interested in how the emerging IT standard gradually stabilized stakeholder cooperation (by reducing resource heterogeneity) and why it eventually led to intensified competition between them that undermined their joint greening efforts.

The analysis allowed us to theorize how cooperation affects coopetitive action in vertical IT standardization for environmental sustainability by reshaping positions of competing firms. Our tentative theorizing reveals the various facets of coopetition in such standardization and explicates their respective implications for large-scale efforts to green an industry.

\section{Empirical Findings}

\subsection{Frame Dynamics}

Our framing analysis specifically focuses on the standardization practices that ultimately triggered participating firms to increasingly question their threat-based frames and become more inclined to appreciate the opportunity-based frames advocated, which eventually put them under a lot of pressure to assess their own role in and contribution to the overall greening effort.

The individuals who took part in the standard initiative generally held opportunity-based frames from the beginning, whereas threat-based frames were largely enacted by the organizations that those individuals represented. This complicated things 
during the early stages because the representatives had a hard time convincing their respective organizations about the advantages the new institutional logic could potentially render. In this sense, the participating individuals shared a viable framing of the MSI standard, but it was misaligned with the different organizations' assumptions, expectations, and knowledge of IT integration. Simply it seemed difficult for competing frames to co-exist.

Another complicating factor was that user organizations were initially unable to clearly articulate their objectives, values, and interests. This situation started to change when a chief technology officer of a consultative organization owned by 15 Swedish transport organizations was enrolled to the network. Over time he came to play an increasingly prominent role and eventually began to represent the road haulage business as a whole. Indeed, as soon as it became clear that the user side appreciated the opportunity-based framing materialized in the early versions of the emerging standard, different IT vendors almost immediately took a much more active stance. They enacted their threat-based frames and sought to understand their potentially negative consequences.

The process that followed was a dialectic exercise where the MSI Group had to manage those competing frames simultaneously. What started with a small group of individuals who jointly co-created a shared framing of IT integration (allowing for rudimentary coupling of mobile IT systems with backend technology without incorporating business critical data from embedded IT capabilities) turned into a large-scale design effort that ultimately resulted in more stable frames of its participants by stimulating them to reconsider their cognitive schemas. While increasingly complex design issues (evolving around embedded technology for environmental sustainability purposes) triggered framing contests that stabilized/destabilized the network, their matured preferences catered for a design of the standard that invited third-party developers and others to engage with previously protected data. However, this eventually led to changed behaviors of truck manufacturers. The intensified competition between them effectively prevented their greening efforts and participation in collective action.

\subsection{Coopetitive Relations}

The standardization effort began when Viktoria (research institute) sought to exploit new digital opportunities with embedded computing and to explore their potential to leverage greening of road haulage firms. Viktoria teamed up with Vehco (vendor of embedded computing) and together they developed the "Eco-Hauler" concept, which was subsequently materialized as a telematics architecture/platform. In brief, it catered for improved driving behavior and reduced fuel consumption by relying on real-time data emanating from embedded technology in the truck. Managers at Volvo became frustrated with this initiative and questioned its potential value by referring to their firm's long and successful history of R\&D based on embedded computing. They even accused the researchers for taking part in inopportune product development. In response, Vehco argued Volvo's R\&D has had little to do with the needs of road haulers and their utilization of sensor data. At the time, Volvo was a member of Viktoria, while Vehco was not. Despite the reaction from Volvo, Viktoria and Vehco continued to jointly promote innovation with digital technology that could render novel opportunities for road haulage firms to manage their complex and distributed work processes. The road haulers themselves, however, kept their eyes on their (institutionalized) "manual" procedures and routines that they thought IT could streamline at best.

Being one of the central actors of the initiative, Hogia thought of itself as the de facto standard provider and was the only vendor that had a proprietary mobile-stationary integration interface based on XML. The standardization group as a whole sought to benefit from the newfound flexibility that XML offered (vis-à-vis other available options) and therefore it decided to go with the Hogia interface. When top managers at Hogia realized what its competitors were up to they investigated whether the current interface prototype posed an infringement of IP related to their proprietary interface. Hogia simply wanted to continue to integrate systems the way they did and feared a widespread use of XML would disrupt the current integration landscape.

The early reactions from Volvo had a huge impact on the subsequent standardization activities. Vehco deliberately downplayed its embedded agenda and as a consequence the standardization group largely focused on conventional mobile-stationary integration issues. Many of the involved actors were pleased with this direction, but the network was destabilized when Gatespace decided to leave the initiative. Being a third-party telematics service provider, it questioned the traditional logistics orientation and argued it was stupid not to zoom in on the connected truck and associated sensor data. Viktoria sympathized with Gatespace but did not have the power itself to adjust the focus. Indeed, the 
Hogia incident consumed a lot of energy and the network had hardly survived a reinitiated discussion on innovative can bus (embedded computing) strategies.

LBC Frakt was a road haulage contractor (member of TRB Sweden) that put the standardization initiative to test when it decided to implement a new digital infrastructure that would rely heavily on the emerging MSI standard. It thought that the standard was superior to extant proprietary interfaces and thereby allowed for flexible IT integration arrangements. However, the offerings made by the MSI members (IT vendors) were largely based on their proprietary approaches that they had pursued in the past. The popular press recognized this and it caused an intense debate in the road haulage industry.

Consequently, LBC Frakt rejected all offers received and instead it decided to revise its already implemented integration interface (originally developed by NL Partner/Locus Scandinavia) based on the MSI standard. During the revision process LBC Frakt realized that the latter interface offered an entirely new and innovative institutional integration language combining embedded, mobile, and stationary computing, but at the same time it contained overly complex things of limited value in the current situation. LBC Frakt therefore decided to join forces with NL Partner/Locus Scandinavia and TRB Sweden to develop a simple order module that would fulfill a basic order management need. The development and implementation of this module triggered MSI Group to pursue a modularization strategy that was expected to spur the diffusion of the MSI standard. The decision to modularize it (and by doing so invent specific applications) paved the way for new and innovative opportunities. Indeed, besides thoughts on using sensors for load measuring and security measures, the original idea to leverage greening of road haulage processes through embedded computing was reenergized.

However, the design discussions evolving around embedded computing and environmental sustainability put pressure on Volvo and Scania to reveal more details about their telematics strategies than they had done before. What was evident was that they did not have much to say in this matter. They largely talked about what they already had achieved and they were reluctant to problematize prevalent assumptions guiding their R\&D efforts. This had a negative impact on the standardization network and things were gradually slowing down. Enacting a "better safe than sorry" approach, however, Volvo and Scania eventually took a step back and encouraged the standardization group to explore potentially interesting capabilities of other actors.

At the same time, DPS came around and being a third-party route optimization service provider it saw plenty of new, exciting digital opportunities with the available MSI standard (in fact, MSI Group was discussing with several third-party firms that were keen to plunge in and contribute). Given the problems with the truck manufacturers, DPS Scandinavia was regarded as a "low hanging fruit" worth exploring in the realm of environmental sustainability. Indeed, Volvo and Scania did not want to lose face and thus applauded the decision to see what route optimization could bring to the table.

The fact that the truck manufacturers handed over the baton to DPS Scandinavia came as a surprise to many of the other MSI actors. DPS was thrilled about the opportunity and went all in to really embed its agenda into the MSI standard. A series of critical design decisions were taken and it was agreed that three additional MSI modules would be built to cater for viable route optimization opportunities. At the time, road haulers had increasingly started to direct their attention to such computing capabilities. Their growing interest further spurred the ongoing adaptation of the MSI standard.

The collaboration between DPS and the MSI Group, however, pushed the design to a level where other actors with route optimization capability questioned its appropriateness (predominantly competing vendors). There were even discussions within DPS about what was going on. People were simply concerned the new modules would undermine the installed base of route optimization software. This pushback caused uncertainty among MSI Group people who were afraid the MSI standard yet again would fail its intended purpose. In the midst of everything, the managing director of Vehco replaced the TRB representative as chairman of MSI Group. This change unfortunately widened the gap between suppliers and users of IT and the capacity of the standard to guide beneficial industry digitalization was at stake. Still the modularization process was completed and the MSI was made available to the road haulage industry in late 2012 .

While the MSI group governed the MSI standard for the Swedish road haulage industry, some road haulers have completed MSI-based integration projects and the standard was also increasingly used as basis for offerings from IT vendors. Several vendors implemented the standard in their software packages, and truck manufacturers promoted it globally throughout their organizations. Beyond the new technological reality created by the standard, the MSI Group was seen by many as a nexus of digital 
innovation in the road haulage industry. The group represented a physical and cognitive arena for valuecreating interactions within the industry that allowed actors to transcend the boundaries that had previously undermined IT integration efforts.

\section{Discussion}

The inherent complexity of interfirm relationships makes it difficult to disentangle the very process of coopetition in such relations and alliances. On the one hand, our case study reveals how and why relations between rivals can result in simultaneous cooperation and competition necessary for integrating heterogeneous technologies into IT infrastructures. On the other hand, our case study illuminates not only the truly fragile nature of coopetition, but also its dependence on adequate managerial intervention. Indeed, mismanagement of the complex evolution of cooperation modes and competitive behaviors may lead to vertical IT standardization efforts taking the wrong turn from a greening point of view.

We have shown that the MSI effort consisted of different facets of coopetition. Combinations of cooperation modes and competition behaviors characterized these facets. Based on our data analysis, we recognized four particular coopetition facets in vertical technology standardization for environmental sustainability. We have analyzed the cooperation modes (non-cooperation, symbolic, and substantive) of different actors involved using Delmas et al.'s [14] framework. In addition, we have analyzed the competition behaviors in each episode by drawing on competition repositioning literature.

The first coopetition facet involved the initial collaboration between Viktoria (research institute) and Vehco (vendor of embedded computing). Being a newly created start-up company, Vehco was the first IT vendor who joined the standardization group. As an integral part of its business strategy to deliver user-oriented and value-creating IT solutions, it had previously carefully investigated the need for a new industry standard capable of integrating diverse technologies in road haulage firms. Unlike most other vendors, Vehco had spoken directly to road haulers and therefore it had in-depth knowledge of their integration requirements. This knowledge ultimately gave Vehco the power to shape the initial actions of the standardization group and made it eligible to force its perception of the road haulers' needs of a new technology standard.

Vehco offered a telematics platform that catered for improved driving behavior and reduced fuel consumption by relying on real-time data emanating from embedded technology in the truck. This platform and its potential relationships to other computing resources in road haulage firms had a significant impact on the initial standardization work. Given its active stance and influential role, Vehco enjoyed the advantage of dominance and could take its preferred position in the emerging new IT integration landscape. Our observation confirms previous studies suggesting that first comers to such alliances can have the advantage of dominancy [29, $25,26]$, which gives them the ability to choose their preferred position as a dominant firm [47].

Vehco saw the standard setting as a means to leverage its commercial progression. While other vendors of embedded, mobile, and stationary IT systems became increasingly aware of the standardization process, however, they believed the collaboration was too much in favor of Vehco with its embedded computing agenda. This did not motivate them to plunge in and contribute to it, but rather pushed most of them into a non-cooperative mode that effectively prevented their full participation in collective action. They were frustrated that Vehco strengthened its business case because of the standardization project and some of them (predominantly truck manufacturers) jointly accused the researchers for taking part in inopportune product development. Lack of actual involvement of competitors made this phase of the project less dynamic and turned it into a largely static endeavor where firms were waiting for others to take action. Accordingly, we call this coopetition facet static coopetition.

The second coopetition facet relates to the classical intellectual property (IP) problem that emerged when Hogia brought its XML-based IT integration interface to the table. Hogia showed a great interest in the MSI standard via its representative and shared a lot of information about its proprietary interface as well as needs of road haulage firms. This helped and inspired the MSI Group during the initial steps of the standard making process. However, a conflict about Hogia's transparency policy emerged between its project representative and top management. The firm therefore investigated whether the developed interface prototype posed an infringement of IP related to its proprietary interface. While Hogia decided to leave the standardization group, it also threatened to take legal action against the standard. The firm viewed the other actors' behavior as a form of free riding [29], which caused it to enter a noncooperation mode [14]. We thus observed an increased competition between Hogia and the other standardization actors. Indeed, these actors strengthened their cooperation to better compete with 
Hogia. Accordingly, we call this coopetition facet intrinsic coopetition.

The third coopetition facet concerns that new actors were keen to be aligned to the standardization network to benefit from its potential opportunities. For example, there were a few IT vendors that joined the MSI Group merely because they wanted to offer their solutions to LBC Frakt. In the literature, this has been recognized as imitative entry behavior [24]. Not surprisingly, however, these actors never applied the MSI standard to their own software and systems, and they did not contribute to the standard setting. They simply engaged in symbolic cooperation [13]. Accordingly, we call this coopetition facet extrinsic coopetition.

The fourth coopetitive facet concerns how pioneer MSI Group members, despite their presence in technical workshop meetings and the benefits the standard could have for them, surprisingly took a passive stance. We observed, similar to Greve [21], that high organizational inertia hindered firms from contributing to the standardization process. Volvo and Scania sought to push toward a stronger mobilestationary orientation by understanding and collecting business critical information about the other participants' requirements and expertise. At the same time though they were reluctant to help the standardization group to improve the embedded part of the standard, which essentially was the initial motivation of the standard makers to have them on board. During this period of the standard setting process, the third-party vendor DPS showed an interest in joining the group. Assessing its capabilities and software, MSI Group members found DPS to be an attractive partner and started to cooperate with it to speed up the standard making process. This cooperation can be described as substantive cooperation [14]. However, Volvo, Scania, and Vehco were unable to handle their conflict of interest with DPS and therefore they considered making an exit. They turned into mere listeners and this had a negative impact on the attempts to go forward and facilitate the diffusion of the standard. Accordingly, we call this coopetition facet asymmetric coopetition.

\section{Implications}

Coopetition as a form of interaction between industry partners with partial congruence of interests has recently created interests among scholars $[8,9$, 11, 45, 46, 32, 17]. Although competition and cooperation as two components of coopetition have been explored in these studies, they have not been studied simultaneously, but rather as two entities living their own lives. In response to this gap, we have studied these two in a joint fashion and scrutinized their coexistence as coopetition facets. In addition, we have also explored the consequences of these facets for environmental sustainability.

In terms of implications for managers, our findings show that joining a standardization consortium requires deliberate compromises and adequate competencies to push the initiative forward at a reasonable pace and to benefit from it. Such consortium, consisting of competitors, is truly fragile because of the conflict of interests that may surface during its evolution. Indeed, the legal issues that are likely to emerge can hinder a standard initiative at best. To prevent occurrence of incidents such the ones we reported, proper regulations of rights and sharing must be in place along with thorough documentation of meetings and agreements. Organizational inertia, other than undermining an individual firm to get the desired profit out of a standard, can prevent the initiative to go forward by affecting other players' cooperation as well. This is especially true if this passivity is coming from prominent actors who are supposed to operate at the center of the network. Indeed, in situations where greening is part of the standardization agenda all participants must find ways to make their individual understanding of environmental sustainability clear and convey it to the others.

\section{Conclusions}

Our study of an IT standardization effort illuminates the value of analyzing aspects of cooperation and competition in an integrated fashion. Based on the 11-year effort, we have identified four different coopetition facets. We have used Delmas et al.'s cooperation framework [14] to analyze the cooperation patterns of actors by distinguishing between different cooperation modes: noncooperation, symbolic cooperation, and substantive cooperation. We have used competition repositioning theories to analyze the rivals' behaviors to see how competition incentives for individual actors have caused them to reposition. Our discussion of the findings indicates the environmental sustainability implications of each facet.

Our study opens new opportunities for future research. First, our study is based on a single case. Although we have analyzed the actors' encounters in detail, applying our approach to multiple cases may help to fine tune the results. Second, our study investigates a vertical standardization project, which makes it an industry-specific work. Applying our approach to a horizontal standardization project can 
help to generalize the results. Finally, a more quantitative approach that measures environmental sustainability impacts may produce interesting insights about the potential greening effects of particular combinations of cooperation modes and competition behaviors.

\section{References}

[1] Anderson, P., and Tushman, M. L., "Technological discontinuities and dominant designs: A cyclical model of technological change", Administrative science quarterly, 1990, pp. 604-633.

[2] Andersson, M., and Lindgren, R., "The MobileStationary Divide in Ubiquitous Computing Environments: Lessons from the Transport Industry", Information systems management 22(4), 2005, pp. 65.

[3] Andersson, M., Lindgren, R., and Henfridsson, O., "Architectural knowledge in inter-organizational IT innovation", The Journal of Strategic Information Systems, 17(1), 2008, pp. 19-38.

[4] Azad, B., and Faraj, S., "Social Power and Information Technology Implementation: A Contentious Framing Lens", Information Systems Journal 21(1), 2011, pp. 33-61.

[5] Bala, H., and Venkatesh, V., "Assimilation of interorganizational business process standards", Information systems research 18(3), 2007, pp. 340-362.

[6] Benford, R. D., and Snow, D. A., "Framing Processes and Social Movements: An Overview and Assessment", Annual review of sociology, 2000, pp. 611-639.

[7] Bengtsson, M., and Kock, S., " Coopetition" in business Networks - to cooperate and compete simultaneously. Industrial marketing management 29(5), 2000, pp.411-426.

[8] Bengtsson, M., Eriksson, J., and Wincent, J., Coopetition dynamics-an outline for further inquiry. Competitiveness review: An international business journal 20(2), 2010, pp. 194-214.

[9] Bengtsson, M., and Kock, S., "Coopetition-Quo vadis? Past accomplishments and future challenges", Industrial Marketing Management 43(2), 2014, pp. 180188.

[10] Chen, M. J., Kuo-Hsien, S. U., and Tsai, W., "Competitive tension: The awareness-motivation-capability perspective", Academy of Management Journal 50(1), 2007, pp. 101-118.

[11] Chen, M. J., "Reconceptualizing the competitioncooperation relationship: A transparadox perspective", Journal of Management Inquiry, 2008.
[12] Christensen, C. M., Suaréz, F. F. and Utterback, J. M., "Strategies for Survival in Fast-Changing Industries". Management Science 44 (12), 1998, pp. 207-220.

[13] Davidson, Elizabeth J. "Technology frames and framing: A socio-cognitive investigation of requirements determination." Mis Quarterly, 2002, pp. 329-358.

[14] Delmas, M. A., and Montes-Sancho, M. J., "Voluntary agreements to improve environmental quality: Symbolic and substantive cooperation", Strategic Management Journal 31(6), 2010, pp. 575-601.

[15] Doz, Y. L., "The evolution of cooperation in strategic alliances: initial conditions or learning processes?", Strategic management journal 17(S1), 1996, pp. 55-83.

[16] Dussauge, P., Garrette, B., and Mitchell, W., "Learning from competing partners: outcomes and durations of scale and link alliances in Europe, North America and Asia", Strategic management journal 21(2), 2000, pp. 99-126.

[17] Elliot, S., "Transdisciplinary Perspectives on Environmental Sustainability: A Resource Base and Framework for IT-Enabled Business Transformation", MIS Quarterly 35 (1), 2011, pp. 197-236.

[18] Garud, R., Jain, S., and Kumaraswamy, A., "Institutional entrepreneurship in the sponsorship of common technological standards: The case of Sun Microsystems and Java", Academy of management journal 45(1), 2002, pp. 196-214.

[19] George, L. M., and Waldfogel, J. (2006). "The New York Times and the Market for Local Newspapers". The American economic review, 435-447.

[20] Gimeno, J., Chen, M. J., and Bae, J., "Dynamics of competitive repositioning: A multidimensional approach", Advances in strategic Management 23, 2006, pp. 399-441.

[21] Greve, Henrich R. "Patterns of competition: The diffusion of a market position in radio broadcasting." Administrative Science Quarterly, 1996, pp.29-60.

[22] Hargrave, T. J., and Van de Ven, A. H., "A collective action model of institutional innovation", Academy of Management Review 31(4), 2006, pp. 864-888.

[23] Hoffmann W.,Lavie D., Reuer J.J.,Shipilov A., "The Interplay of Competition and Cooperation", Strategic Management Journal, Call for paper for a special issue, 2014.

[24] Hsieh, Kai-Yu, and Freek Vermeulen. "The structure of competition: How competition between one's rivals influences imitative market entry." Organization Science 25.1, 2013, pp. 299-319. 
[25] Kalyanaram, Gurumurthy, William T. Robinson, and Glen L. Urban. "Order of market entry: Established empirical generalizations, emerging empirical generalizations, and future research." Marketing Science 14.3_supplement, 1995,pp. G212-G221.

[26] Kerin, Roger A., P. Rajan Varadarajan, and Robert A. Peterson. "First-mover advantage: A synthesis, conceptual framework, and research propositions." The Journal of Marketing, 1992, pp.33-52.

[27] Lado, A. A., Boyd, N. G., and Hanlon, S. C., "Competition, cooperation, and the search for economic rents: a syncretic model", Academy of Management Review 22(1), 1997, pp. 110-141.

[28] Lewis, M. W., "Exploring Paradox: Toward a More Comprehensive Guide", Academy of

Management Review 25 (4), 2000, pp. 760-776.

[29] Lieberman, Marvin B., and David Bruce Montgomery. First-mover (dis) advantages: Retrospective and link with the resource-based view., Graduate School of Business, Stanford University, 1998.

[30] Lindgren, R., Henfridsson, O., and Schultze, U., "Design principles for competence management systems: a synthesis of an action research study", MIS Quarterly, 2004, pp. 435-472.

[31] Loock, C., Staake, T., and Thiesse, F., "Motivating Energy-Efficient Behavior with Green IS: An Investigation of Goal Setting and The Role of Defaults", MIS Quarterly 37(4), 2013, pp. 1313-1332.

[32] Luo, Y., A coopetition perspective of global competition. Journal of World Business 42(2), 2007, 129144.

[33] Malhotra, A., Gosain, S. and El Sawy, O., "Leveraging Standard Electronic Business Interfaces to Enable Adaptive Supply Chain Partnerships", Information Systems Research 18 (3), 2007, pp. 260-279.

[34] Markus, M. L., Steinfield, C. W., and Wigand, R. T., "Industry-wide Information Systems Standardization as Collective Action: The Case of the US Residential Mortgage Industry”, MIS Quarterly, 2006, pp. 439-465.

[35] Melville, N. P., "Information Systems Innovation for Environmental Sustainability”, MIS Quarterly 34 (1), 2010, pp. 1-21.

[36] Nalebuff, B., Brandenburger, A., and Maulana, A. Coopetition, HarperCollinsBusiness, London, 1996.

[37] Narayanan, V. K., and Tianxu Chen. "Research on technology standards: Accomplishment and challenges." Research Policy 41.8, 2012, pp. 1375-1406.
[38] Seidel, S., Recker, J., and Vom Brocke, J., "Sensemaking and Sustainable Practicing: Functional Affordances of Information Systems in Green Transformations", MIS Quarterly 37(4), 2013, pp. 12751299.

[39] Schilling, M. A., "Technology success and failure in winner-take-all markets: The impact of learning orientation, timing, and network externalities", Academy of Management Journal 45(2), 2002, pp. 387-398.

[40] Shrivastava, P., "Environmental technologies and competitive advantage", Strategic management journal 16(S1), 1995, pp. 183-200.

[41] Suarez, F. F., "Battles for technological dominance: an integrative framework", Research Policy 33(2), 2004, pp. 271-286.

[42] Suarez, F. F., and Utterback, J., "Patterns of industrial evolution, dominant designs, and firms' survival. Research on technological innovation", management and policy 5, 1993, pp. 47-87.

[43] Teece, D. J., "Explicating Dynamic Capabilities: The Nature and Microfoundations of (Sustainable) Enterprise Performance", Strategic Management Journal 28, 2007, pp. 1319-1350.

[44] Tegarden, L. F., Hatfield, D. E., and Echols, A. E., "Doomed from the start: What is the value of selecting a future dominant design?", Strategic Management Journal 20(6), 1999, pp. 495-518.

[45] Tsai, W., "Social structure of "coopetition" within a multiunit organization: Coordination, competition, and intraorganizational knowledge sharing", Organization science 13(2), 2002, pp. 179-190.

[46] Walley, K., "Coopetition: An Introduction to the Subject and an Agenda for Research", International Studies of Management and Organization 37 (2), 2007, pp. 11-31.

[47] Wang, R. D., and Shaver, J. M., "Competition- driven repositioning", Strategic Management Journal 35(11), 2014, pp. 1585-1604.

[48] Watson, R. T., Boudreau, M. C. and Chen, A. J., "Information Systems and Environmentally Sustainable Development: Energy Informatics and New Directions for the IS Community", MIS Quarterly 34 (1), 2010, pp. 23-38.

[49] Wigand, R. T., Steinfield, C. W., "Information technology standards choices and industry structure outcomes: The case of the US home mortgage industry", Journal of Management Information Systems 22(2), 2005, pp. 165-191. 